\title{
Agent-based land-use models: a review of applications
}

3

4

Robin Matthews, Nigel Gilbert, Alan Roach, Gary Polhill, \& Nick Gotts

R B Matthews (Corresponding author) • J G Polhill • N M Gotts

Integrated Land Use Systems Group

Macaulay Institute

Craigiebuckler

Aberdeen AB15 8QH

United Kingdom.

Email: r.matthews@macaulay.ac.uk

Tel: +44 (0) 1224498261

Fax: +44 (0) 1224311556

N G Gilbert • A Roach

Department of Sociology

University of Surrey

Guildford

Surrey GU2 7XH

United Kingdom.

Date of the manuscript draft: 27 March 2007

Manuscript word count (including text, references, tables, and captions): 9008

42

* This paper arises from research conducted as part of the UK Research Councils' RELU Programme (award number RES-224-25-0102). RELU is funded jointly by the Economic and Social Research Council, the Biotechnology and Biological Sciences Research Council and the Natural Environment Research Council, with additional funding from the Department for Environment, Food and Rural Affairs and the Scottish Executive Environment and Rural Affairs Department. 


\section{Abstract}

Agent-based modelling is an approach that has been receiving attention by the land use modelling community in recent years, mainly because it offers a way of incorporating the influence of human decision-making on land use in a mechanistic, formal, and spatially explicit way, taking into account social interaction, adaptation, and decision-making at different levels. A number of such models are now beginning to appear - it is timely, therefore, to review the uses to which agent-based land use models have been put so far, and to discuss some of the relevant lessons learnt, also drawing on those from other areas of simulation modelling, in relation to future applications.

In this paper, we review applications of agent-based land use models under the headings of (a) policy analysis and planning, (b) participatory modelling, (c) explaining spatial patterns of land use or settlement, (d) testing social science concepts, and (e) explaining land use functions. The greatest use of such models so far has been by the research community as tools for organising knowledge from empirical studies, and for exploring theoretical aspects of particular systems. However, there is a need to demonstrate that such models are able to solve problems in the real world better than traditional modelling approaches. It is concluded that in terms of decision support, agent-based land-use models are probably more useful as research tools to develop an underlying knowledge base which can then be developed together with end-users into simple rules-of-thumb, rather than as operational decision support tools.

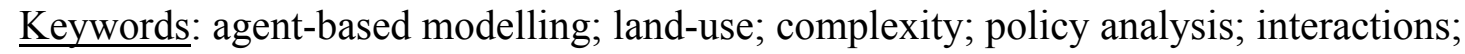
decision-making 


\section{Introduction}

Agent-based modelling has recently been receiving attention in the land-use modelling community, mainly because it offers a way of replacing transition probabilities or differential equations at one level (e.g. populations) with decision rules of entities at a lower level (i.e. individuals or groups of individuals) along with the appropriate environmental feedbacks (Verburg, 2006). Originating from the field of artificial intelligence, and with parallels with Individual Based Modelling (IBM) in ecology (Huston et al., 1988), agent-based models (ABMs) consist of a number of 'agents' which interact both with each other and with their environment, and can make decisions and change their actions as a result of this interaction (Ferber, 1999). Agents may contain their own 'model' of their environment (which may not necessarily be complete or even true) built up from its interactions with it. The behaviour of the whole system depends on the aggregated individual behaviour of each agent. This allows the influence of human decision-making on the environment to be incorporated in a mechanistic and spatially explicit way, also taking into account social interaction, adaptation, and decision-making at different levels. Agents can interact either indirectly through a shared environment and/or directly with each other through markets, social networks, and/or institutions. Higher-order variables (e.g. commodity prices, population dynamics, etc.) are not specified as they are in conventional econometric techniques, but, instead, are emergent outcomes.

The earliest published use of agent-based simulation in relation to land use appears to be the study of Lansing \& Kremer (1993), who modelled irrigation systems in Indonesia. Since then, a number of agent-based land-use models (ABLUMs) have been developed (see recent reviews by Parker et al., 2002; Bousquet \& Le Page, 2004; Hare \& Deadman, 2004). There has been a gradual progression of such models from relatively abstract representations, not 
1 necessarily related to real-world situations, which were used to explore conceptual aspects of

2 spatially explicit systems (e.g. Epstein \& Axtell, 1996), through to more complex

3 representations of socio-ecological systems (e.g. Berger \& Ringler, 2002; Hoffmann et al.,

4 2002) based on empirical data (e.g. Deadman et al., 2004). Recent versions of some of these

5 models have now started to be applied to answer specific real-world questions. It is

6 noteworthy that other areas of simulation modelling have been through similar progressions -

7 Sinclair \& Seligman (1996), for example, drew parallels between the growth and development

8 of crop simulation models and human development, identifying four phases: birth/infancy,

9 juvenile, adolescent, and maturity. For this class of models, the euphoric infancy and juvenile

10 stages in the 1960s were characterised by the expectation that they could provide the answers

11 to questions in many areas of crop science, and led to the development of highly detailed

12 'comprehensive' models. However, a failure to deliver many of these answers, particularly in

13 an operational context, led to a re-evaluation of the basic concepts of crop modelling and the

14 development of simpler models during the adolescence stage in the 1970s. This resulted in a

15 growing awareness of the limitations of such models and a better understanding of the nature

16 of these limitations during the maturity phase in the 1990s. Matthews \& Stephens (2002)

17 subsequently extended this analogy by examining the 'employment' these models had,

18 analysing some of the problems that had been encountered along the way, and made

19 suggestions as to how such models might develop in the future.

20 ABLUMs have not yet had the same length of time for development as crop models have,

21 but because there is increasing pressure by funding agencies to develop tools that are of

22 practical use by end-users and other stakeholders, we believe that it is timely to review the

23 uses to which ABLUMs have been put so far, and to discuss some of the relevant lessons

24 learnt from other areas of simulation modelling in this respect. In this way, it is hoped that

25 this may provide a guide to unproductive avenues of activity which should be avoided, or at 
1 least stimulate careful thought about the likely success of such avenues before they are

2 embarked on.

\section{Applications}

4 Various classification systems have been proposed for ABLUMs (e.g. Hare \& Deadman, 5 2004; Boero \& Squazzoni, 2005) but for the purposes of this review we discuss such models

6 primarily according to the purposes for which they were developed. We have identified five

7 broad areas - policy analysis and planning, participatory modelling, explaining spatial

8 patterns of land use or settlement, testing social science concepts, and explaining land use

9 functions, although it is recognised that several models fall into more than one category. In

10 the following subsections, we discuss the modelling efforts in each of these five categories in

11 turn.

\section{Policy analysis and planning}

ABLUMs have been or are being used for policy-related research in a range of topic areas. For example, Balmann (1997) developed the AgriPoliS model to demonstrate the existence of path dependence in the evolution of land use following German reunification - depending on the starting point, different equilibria could be reached, running counter to general thinking in agricultural policy. He subsequently used the model to investigate the effect of reducing price support and introducing compensation payments under the EU Agenda 2000 policy in the Hohenlohe region of Germany (Balmann et al., 2002). Results showed that average farm size and income increased at a greater rate under the Agenda 2000 scenario, and that production efficiency increased due to higher returns to scale and lower rental values. Happe (2004) expanded on this work by evaluating the impact of a number of agricultural policies on regional structural change in the region, and showed that the effects of different ways of decoupling payments from farm production differed significantly in the short term, but not in the long term. Berger (2001) further developed the model to study the dynamic impacts of 
1 free trade policies on a large agricultural region in Chile in terms of the diffusion of specific

2 innovations and the resulting resource use change. The study suggested that market-driven

3 technological change would probably take much longer than envisaged by the Chilean

4 government at that time, and that credit schemes, public investment in irrigation facilities, and

5 fertiliser subsidies would lead to increased agricultural employment.

$6 \quad$ Weisbuch \& Boudjema (1999) used an ABM approach to understand which agri-

7 environmental policies would bring about robust outcomes despite the inherent uncertainties

8 at the micro-level about environmental issues and how such policies could be implemented,

9 given the heterogeneity in interests and cultural values of the people involved. The results

10 showed that global average information was not sufficient to predict adoption rates of agri-

11 environment schemes - for the same average characteristics, uptake could be as low as $0 \%$ or

12 as high as $100 \%$ - and that individual information on farmers and their networks was

13 necessary. For example, highest rates of adoption were obtained when efforts were focused on

14 pivotal individuals such as early adopters and influential leaders - a conclusion, therefore,

15 was that financial gains from the grants should be large enough to ensure participation of

16 enough early adopters. The assumption of full rationality produced adoption rates on a

17 continuous scale between 0 and $100 \%$, whereas the assumption of bounded rationality by

18 agents tended to produce clusters close to $0 \%$ and $100 \%$ with only a few cases in between.

19 System resilience was also observed - changes in certain parameters resulted in little change

20 in particular response variables as long as the system remained in one dynamical regime, but

21 at certain values there would be a sudden change as it shifted into another regime (Weisbuch,

22 2000).

23 As part of the same study, Deffuant et al. (2002) explored the processes of innovation

24 diffusion of organic farming. Their model extended the classical approach to innovation

25 diffusion by distinguishing between the effects of initial information passed to a subset of 
1 farmers from institutions, and subsequent discussion among farmers themselves, and also

2 represented opinions and uncertainties as continuous variables, in contrast to most models,

3 which treat them as discrete entities. The model predicted higher levels of adoption of organic

4 farming than was actually observed, which they speculated to be due to cultural resistance

5 and/or lack of information, highlighting the need for an ABM that takes these factors into

6 account. In a comparable study, Sengupta et al. (2005) investigated farmer uptake of a

7 Conservation Reserve Program in southern Illinois in which payments were made by the

8 USDA to retire land highly susceptible to erosion from production. Based on survey data,

9 they used a decision-tree approach to classify farmers into three different types: 'opportunists'

10 (profit-maximising, commercial farmers), 'mixed' (medium-sized farms), and 'enrolees'

11 (small farmers, retirees). Results indicated that an ABM gave a closer match to actual land

12 use data than did a traditional profit-maximisation model (GEOLP).

13 In the examples just discussed, the models were used to explore the likely impact of

14 specific real-world policies. A number of studies have also examined the influence of more

15 generic and abstract policies on the behaviour of agents within a system. For example,

16 Janssen et al. (2000) used an ABM to explore co-evolution between pastoralist behaviour and

17 different policies and institutions relating to the management of rangelands. Policies

18 examined were (a) a conservation policy aiming at minimising the negative impacts of human

19 activities, (b) a stabilisation policy aiming at maximising the long-term welfare of society,

20 and (c) a non-interventionist free market policy in which pastoralists made their own

21 management decisions. Results showed that strongly fluctuating stocking density led to the

22 best financial and ecological consequences, and interestingly, that regulatory policies reduced

23 the amount of learning by the agents, but kept the rangeland in relatively good condition.

24 Pastoralists that evolved under the free-market regime were able to outperform those that

25 evolved under the conservation policy regime, as 'risky' behaviour was tolerated less in the 
1 former and therefore removed from the system through bankruptcy. Janssen (2001) used a

2 similar approach to explore the impact of different policies on management of lake

3 eutrophication, taking into account farmers' use of phosphorus for agricultural purposes. In

4 this model, farmers based their decisions on the magnitude and uncertainty of the returns from

5 their activities, and were taxed according to the amount of phosphorus in the lake. Results

6 showed that the impact of tax varied depending on the conditions - in cases where farmers

7 had a low tolerance of uncertainty and were easily satisfied in terms of their returns,

8 increasing tax did not lead to a change in behaviour. Where farmers had a high tolerance of

9 uncertainty and low targets for minimal returns, however, the long-term resilience of the

10 ecosystem could be improved without significantly reducing the returns of the farmers.

11 Increasing the target level for returns and increasing the uncertainty of returns both led to a more intensive use of phosphorus and to higher levels of phosphorus in the lake. A similar agent-based approach was used in a comparable study by Möhring \& Troitzsch (2001).

Other studies make the point that ABMs are a useful tool for analysing proposed policy changes, but do not provide examples of their application. Vanclay et al. (2003), for example, describe the FLORES model which was built with the aim of providing a tool for policymakers to anticipate the likely outcome of proposed decisions on communities living at or near forest margins in tropical areas, while Ligtenberg et al. (2004) describe the development of an $\mathrm{ABM}$ as a support tool for spatial planning, and its use in exploring different ways in which decisions regarding land use could be made - all actors having equal power, one actor

21 being the most powerful, and consultation.

\section{Participatory modelling}

It is often considered that ABLUMs have particular advantages in a participatory context, as ABMs correspond quite closely to the ways in which stakeholders generally think about the 
1 actions of and interactions between decision-makers, and can therefore criticise the models or contribute to their design in ways that make use of their practical knowledge.

The CORMAS group, in particular, has focused on the use of ABMs in a participatory way

to solve specific problems, the work of which has been reviewed by Bousquet et al. (2002).

Much of their work has been to develop agent-based modelling as a tool in role-playing games (RPGs) which they view as being particularly appropriate due to a good match of the characteristics of both (Bousquet et al., 2002:249). In using the SHADOC model in Senegal, for example, players were assigned roles which include their social status, their function in the system (e.g. water course regulator, pumping station manager, credit allocation manager), their goals, and various other rules (Barreteau et al., 2001). The models were used to provide the biological, economic, spatial and temporal dynamics of the decisions made by the RPG players. The players learnt how to see the overall system from different perspectives, although one issue was out-of-bounds for discussion - that of the effect of caste on social dynamics. Use of the SHADOC model in the RPG context is an example of the second level of participation as defined by Parker et al. (2002) - the model had been constructed previously (Barreteau \& Bousquet, 2000), and a simplified version was developed from this for use in the RPG. SelfCORMAS (d'Aquino et al., 2003), on the other hand, focused on building the model together with stakeholders right from the beginning, representing the first level of participation defined by Parker et al. (2002). In this case, the structure of the model itself was an output of the process. Both approaches were found to be useful - the Level 1 approach for defining the model and obtaining information on social dynamics and individual decisionmaking, while the ready-made model of the Level 2 approach provided a focus for discussion.

Etienne et al. (2003) describe how the MEJAN model was used in a step-wise fashion to incorporate the perspectives of the different players in the Causse Méjan region (foresters, farmers and the National Park of Cévennes rangers) where grassland-dominated ecosystems 
1 used for grazing was endangered by pine invasion. Through interactive use, this helped to

2 give each of the three types of stakeholder a greater understanding of the impacts of their own

3 decisions on the others and on the environment, and highlighted the need for compromise and

4 more collective management of the pine woodlands. Similarly, Boissau et al. (2004) and

5 Castella (2005) describe the development and use of SAMBA as a tool in role-playing games

6 in Vietnam, making the point that such models are being increasingly used in negotiation

7 platforms to accompany social changes. Other participatory models mentioned by Bousquet et al. (2002) include STATEGENES (plant genetic resource management in Madagascar) and

$9 \quad$ SYLVOPAST (looking at compromises between livestock farmers and foresters).

The FLORES model was also developed using a participatory approach (Vanclay et al., 11 2003) at a workshop was held in Bukittinggi in Sumatra, Indonesia, to which a number of researchers from different disciplines were invited. Groups were formed with the responsibility for developing components of a coupled social-environmental model. A related model (ZimFlores) was also constructed in participatory fashion for use in the communal lands surrounding the Mafungautsi forest in Zimbabwe (Prabhu et al., 2003).

\section{Testing hypotheses of land-use and settlement patterns}

Several of the models reviewed were designed to test and evaluate hypotheses relating to land-use and settlement patterns. The SLUDGE model, for example, was developed to explore the impacts of distance-dependent spatial externalities and transportation costs on patterns of urban development and land-use (Parker \& Meretsky, 2004). The approach

21 combined a cellular automaton representing the landscape with an ABM describing land-use decisions of individual parcel managers, with parcel-manager decisions determining the landuse of individual cells, which in turn influenced the decisions made through land rents.

24 Conflicts between urban and rural land uses affected the payoffs to particular land uses.

25 Results demonstrated the relative economic inefficiency of land-use fragmentation, and that 
1 increased conflict between urban and rural land-uses resulted in more compact urbanisation

2 patterns, that the rural-urban fringe expanded inefficiently if agricultural profitability was

3 affected by proximity to urban areas, and that conflicts between urban land users could result

4 in fragmentation patterns of urban development similar to those observed in the real world.

5 The SprawlSim project was initiated to develop a suite of simulation tools for testing similar

6 ideas and hypotheses on the mechanisms behind growth and spatial patterns of cities in North

7 America, with a view to identifying ways in which the process could be controlled (Torrens,

8 2002). The approach also involved linking a cellular automata to ABMs and more traditional

9 land-use and transport models to address issues of local decision-making as well as top-down

10 planning in determining sprawl patterns. Several metrics were developed to quantify sprawl

11 patterns to enable comparison of model predictions with those observed in real cities, but to

12 our knowledge, any insights gained from this work have not yet been published.

13 On a related theme, Brown et al. (2004) used an ABLUM to evaluate the effectiveness of

14 locating greenbelts near developed areas on delaying the spread of development. Their results

15 showed that the effectiveness was influenced by the location and width of the greenbelt, but

16 that landscape aesthetic quality and assumptions about where service centres were located

17 were also important. Loibl \& Toetzer (2003) used much the same approach in their STAU-

18 Wein model to understand growth and densification processes in suburban Vienna. The model

19 simulated polycentric development of suburban systems, taking into account population

20 migration and commercial start ups controlled by regional and local factors. Household agents

21 made their choices of where to live based on factors such as large and small scale accessibility

22 (travelling time to the core city, access to motorways), land prices, landscape attractiveness,

23 social and commercial services supply, traffic exposure obstacles, and land use zoning

24 constraints. Rajan \& Shibasaki (2001) also used an ABLUM to study the dynamics of

25 urban/rural land use, this time in Thailand, with returns from agricultural land being 
1 calculated as a function of crop yields and the prevailing prices, and the spread of urban areas

2 due to demographic pressures.

3 The SIMPOP model described by Sanders et al. (1997) was developed to simulate the

4 evolution of settlement patterns over longer time periods, starting with scattered agricultural

5 villages and ending with functionally diverse, competing, hierarchical urban settlements.

6 Results showed that without industrialisation included, the system became more complex

7 (increasing commercial and administration functions) up to about 1500 years, but then could

8 not evolve any further. The dynamics of the system was only renewed with the introduction of

9 industrial activities. Three components at different scales were shown to be necessary for the

10 evolution of a hierarchical system: (a) a cell needed to produce an economic surplus, (b) there

11 needed to be competition between cells, and (c) there needed to be the ability to adapt to new

12 innovations to create new production functions. Distributions of settlement sizes were found

13 to follow a power-law distribution with the slope increasing exponentially with time.

14 Two related ABMs were developed to test hypotheses relating to settlement patterns of

15 ancient societies in meso-America. The model of Dean et al. (2000) contained agents

16 representing households and a detailed biophysical environment to study the cause of the

17 collapse of the Anasazi culture in Long House Valley in north-eastern Arizona around 1300

18 AD. Although it predicted significantly higher household numbers and settlement sizes than

19 were observed in the archaeological record, it was able to simulate the temporal dynamics of

20 these variables over most of the study period reasonably well. However, it was unable to

21 capture the complete abandonment of the valley in $1300 \mathrm{AD}$, prompting the authors to

22 conclude that environmental factors alone were not the only reason for the collapse. Kohler et

23 al. (2000) used a version of the same model to show that, for Pueblo people living in south-

24 western Colorado between $900 \mathrm{AD}$ and $1300 \mathrm{AD}$, water availability could explain variation in

25 the distribution and size of villages. However, as with the model of Dean et al. (2000), a 
1 decrease in the goodness of fit towards the end of the simulated period indicated that the

2 importance of rainfed agriculture may have declined at this time, possibly due to

3 intensification (which the model did not simulate), or that water shortages may have forced

4 farmers to stay closer to water supplies rather than settle in the most productive areas.

Hoffmann et al. (2002) used the LUCIM model to investigate the factors involved in the

6 deforestation and subsequent reforestation of Indiana over the last 200 years. Their results

7 showed that farmers' decisions were sensitive to prices and tax levels, that reforestation was

8 mainly on the steeply sloping areas, and that there was a pattern of rapid deforestation

9 followed by slow afforestation, all of which were observed empirically. Evans \& Kelley

10 (2004) subsequently used the model to evaluate scale-dependence issues. The LUCITA

11 model, from the same group, was developed to investigate patterns of settlement and land-use

12 change in the Altamira region of Brazil (Deadman et al., 2004).

13 Among other applications of this general type, Huigen (2004) developed the MameLuke

model to investigate the interactions between farmers and loggers in the Philippines, while the

15 ABLOoM model (Otter et al., 2001) was used to simulate the relative location patterns of

16 households and firms, with a focus on two distinct land use patterns: clusters and sprawl.

17 Testing social and economic science concepts

18 A number of models have been developed to explore the relative competitiveness of

19 different strategies that land-managers could adopt, and the resulting rise of institutions

20 influencing their behaviour, particularly where social dilemmas were present (see Gotts et al.,

212003 a for a recent review). A good example of how complex societal behaviour can emerge

22 from simple local rules is the study of Lansing \& Kremer (1993) referred to above. It had

23 been observed that groups of farmers (subaks) in Indonesia staggered the times of planting of

24 their rice crops to balance the two opposing constraints of water-sharing and pest control,

25 mediated by traditional ceremonies at so-called 'water temples'. If all fields were planted at 
1 the same time, there was not enough water to irrigate them all, but if they were staggered too

2 much, pest damage was much higher. Using an ABM in which farmer agents imitated the

3 time of planting of their neighbours that gave the highest yields, Lansing \& Kremer were able

4 to show that irrigation schedules able to produce high yields and withstand drought and pest

5 attack emerged, regardless of initial distribution of cropping patterns, and parameters such as

6 water flow rates and pest incidence. Within 8-35 years, depending on ecological conditions,

7 subaks spontaneously self-organised into a pattern where all subaks were at or near a local

8 optimum.

In Thailand, Becu et al. (2003) used the CATCHSCAPE model to investigate the impacts of upstream irrigation management on downstream agricultural viability in catchments where

11 there is the potential for conflicts. They analysed the outcomes of a number of scenarios relating to water management: (a) a baseline scenario, in which farmers were not permitted to convert forest into agricultural plots, all agents were honest, and negotiations between managers were fair, (b) a conflict scenario, in which upstream managers imposed their will on those downstream with no negotiations taking place, (c) a dishonesty scenario, in which some farmers took more water than was agreed, and (d) a water shortage scenario, consisting of ten years of low rainfall. The conflict scenario resulted in a change in the distribution of cropping patterns with more dry season cropping occurring upstream and less downstream, while the dishonesty scenario resulted in greater polarisation of wealth between farmers, with many more poor farmers and an overall drop in dry season cropping. Perhaps surprisingly, the water 21 shortage scenario gave similar results to the dishonesty scenario.

The FEARLUS group at Macaulay Institute have focused on investigating theoretical aspects of strategies of land-use selection and the impacts that the use of these strategies have at the landscape level. Results showed that the performance of specific selection strategies involving imitation of neighbours' choices as a basis for selection of land-use depended on 
1 the rate of change of biophysical and economic conditions, and on the strategies followed by

2 other agents (Polhill et al., 2001). Subsequent work showed that the usefulness of imitation

3 depended on the quality of the possible targets of imitation, on the imitation strategy used,

4 and the spatial heterogeneity of the environment. Following this, the concept of an 'aspiration

5 threshold' was investigated, defined as the economic return that an agent requires from a

6 parcel of land to persist with current land-use (Gotts et al., 2003b). If the return from a parcel

7 of land in a given year did not reach the aspiration threshold, the agents would choose a new

8 land-use in some way, for example, at random or by imitating a neighbour. Results showed

9 that the optimum aspiration threshold depended on environmental heterogeneity as well as the

10 break-even threshold, i.e. the point at which the returns from a given land parcel balanced the

11 costs of obtaining them. Recent work by the group has investigated case-based reasoning

12 (CBR) as a basis for decision-making (Izquierdo et al., 2004). CBR consists of 'solving a

13 problem by remembering a previous similar situation and by reusing information and

14 knowledge of that situation', on the assumption that if a solution turned out to be satisfactory

15 when applied to a previous problem it might also work in a similar situation. Work so far has

16 shown that agents playing the Prisoner's Dilemma game using CBR decide more often to

17 cooperate rather than defect.

Milner-Gulland et al. (2006) describe the use of an ABM to investigate the trade-offs in

allocation of wealth by households between capital and livestock in the rangelands of

Kazakhstan. Pastoralists have migrated for centuries between the summer and winter pastures

21 to exploit seasonal differences in forage availability, but following independence from the

22 Soviet Union in 1991, the rural economy collapsed and these migrations stopped. Recovery of

23 the rural economy is now a priority, and the purpose of the study was to explore possible

24 pathways by which this could occur and particular policies that might promote it. Results

25 showed that increasing returns to capital had little effect on the livestock system, although it 
1 did alter the balance of agent strategies to some extent. Winter forage availability was the key

2 determinant of overall livestock numbers, rather than summer biomass production, while

3 availability and price of winter fodder was an important determinant of the livestock

4 productivity of the system. Due to the costs involved, seasonal migrations were predicted to

5 be worthwhile only for large successful flocks. The authors make the point that other

6 modelling approaches besides ABM would probably have given similar results.

\section{$7 \quad$ Modelling landscape functions}

8 Although it could be argued that land use in itself is not as important as its effects on the

9 biophysical functioning of the landscape (e.g. provision of ecosystem services, maintenance

10 of biodiversity), so far there have been only a few examples of ABMs being used to

11 investigate the linkages between human behaviour and biophysical processes occurring in the

12 landscape.

One such example is that of the IMSHED (Integrated Model for Simulating Household and Ecosystem Dynamics) developed to investigate the impact of a growing rural population on forests and giant panda habitats in China (An et al., 2005). Agents represented households, with fuel-wood demand being modelled as a function of household size, the presence of older

17 people, and cropped area of maize and potatoes. Agents could also switch to using electricity rather than fuel-wood depending on a range of factors. Forests in the landscape were able to grow and die in the absence of human interference, with their volume being reduced when fuel-wood was harvested from them. Results showed that implementing policies that

21 encouraged family planning, out-migration, or increased use of electricity could result in 22 preserving panda habitats to various degrees.

The PALM model also represents an attempt to link agent decision-making to the 24 underlying biophysical processes, this time for soil nutrient dynamics in the mid-hills of 
1 on validation of the biophysical component against field data (Matthews \& Pilbeam, 2005). In

2 a third example, SYPRIA model was developed to explore the impacts of different scenarios

3 on trends of tropical deforestation and cultivation and their effect on carbon sequestration in

4 the southern Yucatán peninsular region of Mexico (Manson, 2004). However, published

5 papers so far have focused on the use of genetic programming as an agent decision-making

6 approach (Manson, 2005a; Manson, 2005b), and have not yet looked at the impact of human

7 decisions on carbon sequestration.

\section{Discussion}

9 There is no doubt that the largest use of ABLUMs so far has been by the research

10 community. This is because models are primarily research tools - for most scientists, using

11 models as a way of organising and utilising information is a process taken for granted. A valid

12 question, however, is when should ABM approaches be used in a research context? Hare \&

13 Deadman (2004) list the advantages of ABM as its ability to couple social and environmental

14 models, to incorporate the influence of micro-level decision-making in environmental

15 management, and to study the emergence of collective responses to environmental

16 management policies. Parker et al. (2002) additionally include the ability to model decision-

17 making at different levels (e.g. individuals, organisations), and adaptive behaviour at the

18 individual or system level.

19 Certainly, a major advantage of ABLUMs is their ability to model individual decision-

20 making entities, taking into account the interactions between them, and linking these micro-

21 scale decisions to macro-scale phenomena. Most land use systems are characterised by a large

22 degree of heterogeneity, particularly at the individual farm level with between-farm

23 variability in terms of farmer aspirations and attitudes, and within-farm variability in

24 resources. Many existing approaches focus on the behaviour of 'average' farmers - agent- 
1 based modellers, however, would contend that this heterogeneity is an essential characteristic

2 in its own right that influences the dynamics of such systems. Thus, ABLUMs are likely to be

3 of benefit in modelling systems where heterogeneity between the entities and the interactions

4 between them is important to the final outcome. Weisbuch \& Boudjema (1999), for example,

5 found that average information was not able to predict adoption rates of agri-environment

6 schemes. Evans \& Kelley (2004) too found an agent-based approach useful in the LUCIM

7 model because of the heterogeneity between households in Indiana. Grimm et al. (1999) note

8 that individual variation has also been a major reason that Individual Based Models (IBMs)

9 have been used in ecology, and draw a distinction between 'pragmatic' and 'paradigmatic'

10 use of such models - pragmatic is where individual variation is an intrinsic characteristic of

11 the phenomena being investigated, and paradigmatic is where it is assumed the existing theory

12 is fundamentally incorrect - and gives examples of models used in each way.

13 A second advantage is that of being able to incorporate social processes and non-monetary

14 influences on decision-making. Kohler et al. (2000) saw agent-based approaches being useful

15 where there is evolution of social norms or social structure, or the presence of social

16 dilemmas and common pool resource issues, and Matthews \& Selman (2006) mention their

17 potential ability to incorporate human institutions (i.e. rules and norms) as an advantage.

18 Axelrod (1997) has explored the emergence of cooperation using agent-based approaches,

19 while Gotts et al. (2003a) have reviewed in detail the contribution that agent-based modelling

20 has made to the understanding of social dilemmas. Evans \& Kelley (2004) stress the relative

21 importance of non-monetary factors such as parcel size and educational attainment in land use

22 decisions, which justified the use of ABM in their LUCIM model. Similarly, Izquierdo et al.

23 (2003) explored the influence of social approval on farmers' decisions to use phosphorous

24 fertiliser with the risk of polluting shared water courses. 
1 The ability to link social and environmental processes is a third major advantage of

2 ABLUMs, providing a way of studying human-ecosystem relationships with the ultimate aim

3 of developing principles for managing real coupled human-environment systems (Janssen et

$4 a l ., 2000)$. Although not all problems lend themselves to coupling social and environmental

5 processes, there are many cases where human-environmental interactions are non-linear, with

6 the environment being affected by individual decisions which in turn impact on the

7 environment, potentially leading to complex systems behaviour. For example, gradual

8 changes in slow variables can result in thresholds suddenly being reached when unexpected

9 behaviour may be triggered (Scheffer \& Carpenter, 2003). In such cases, it is important to

10 know under what conditions the dynamics of a land-use system become unpredictable or

11 radically change its mode of functioning, and what the impacts of different human responses

12 are likely to be. Such 'catastrophic' behaviour can often be accompanied by hysteresis, when

13 the forward trajectory of a process is not the same as its return trajectory. Carpenter \&

14 Cottingham (2002) give an example of the build-up of phosphorus in lakes causing a sudden

15 change in the eutrophication level to a new stable state which is difficult to reverse even if the

16 phosphorous level is lowered. Such examples of 'surprises' should prompt further

17 investigation as to why they occurred. Lynam (2002), for example, found that increasing the

18 cash requirements of households counter-intuitively increased average household wealth,

19 which he found was due to poorer households switching from maize to cotton production,

20 thereby increasing their income by saving on expensive inputs.

21 While there are many interesting research questions to which ABLUMs can be applied,

22 there is a growing appreciation that there is also a need to make the use of models in research

23 more relevant to problems in the real world, and also find effective means of knowledge

24 exchange between modellers and potential beneficiaries (Ramanath \& Gilbert, 2004). Both of

25 these can be helped considerably by the latter participating in varying degrees in the 
1 development of the models. Parker et al. (2002) distinguish three levels of participation: (a)

2 where stakeholders are involved at all stages of model development, including model

3 conceptualisation, building and use, (b) where stakeholders are not involved in model

4 building, but are involved in model running, and (c) where models are presented to policy

5 makers as ready-made software packages with the ability for the users to alter model

6 parameters to test various policy options. The work of the CORMAS group described above

7 falls into the first two of these categories, and closely resembles the process of 'mediated

8 modelling' described by van den Belt (2004). The strength of the mediated modelling

9 approach is that, in the process of model construction or use, stakeholders are exposed to

10 other viewpoints of the same problem, which are expressed explicitly in the form of a

11 simulation model enabling them to explore different options they may have. Downsides of the

12 mediated modelling approach include the time and cost of involving stakeholders and

13 maintaining their motivation, possible bias in the stakeholders selected, lack of academic

14 credibility of the resulting models, the possibility of a poorer representation of the real-world

15 system than if just scientists had been involved, and difficulties in validating the resulting

16 models. However, van den Belt (2004) argues that 'buy-in' and trust in a model by the

17 participants are more important in this context than its numerical accuracy.

None of the ABLUMs we reviewed fell into the third category of Parker et al. (2002), i.e. specifically designed as Decision Support Systems for direct use by end-users, but experience in other more mature areas of simulation modelling suggest that at some stage they may be

21 promoted as such tools (McCown, 2002b). However, it should be noted that such DSS tools

22 have had a chequered history in many fields. For example, McCown et al. (2002a) observed

23 that there are surprisingly few examples of successful use of farming systems models as

24 decision-support tools by farmers despite their wide use in research studies and the fact that 25 many of them have been specially tailored for use by farmers. They ascribed this to a poor 
1 understanding by researchers of the actual process of decision-making by farmers and the role

2 decision-support tools may play in this process. Likewise, Stephens \& Middleton (2002)

3 identified several factors which have contributed to the lack of success of crop models as

4 decision support tools, which included model construction issues such as an inappropriate

5 focus on scientific questions rather than questions of relevance to end-users, marketing and

6 support issues such as poor dissemination, lack of training, and technical issues such as poor

7 access to hardware \& software, lack of input data, and poor user interfaces. They concluded

8 that simulation models are probably more useful as research tools to provide solutions to

9 constraints which can then be developed into simple rules-of-thumb, rather than as

10 operational decision-support tools. Instead of incorporating such models directly into decision

11 support tools and handing them to end users, a better approach may be to use them wherever

12 possible in close consultation with the latter to develop an underlying knowledge base

13 relevant to their needs. Models seen as tools to aid the 'learning-in-action' process may be

14 more likely to be used than those seen as repositories of knowledge (McCown, 2002a).

15 On the other hand, Lempert (2002) argued that the reason ABMs have had limited impact

16 in policy-making is because up to that time they had been predominantly used in 'predictive'

17 mode to predict futures that in reality are not accurately predictable. Instead, he suggested that

18 they should be used in conditions of 'deep uncertainty', where there is no agreement by

19 stakeholders on 'correct' decisions. He suggests an 'exploratory modelling' approach

20 whereby ensembles of scenarios - perhaps millions of model runs - are used to represent

21 possible futures, and criteria such as robustness, resilience, and stability are used to compare

22 alternative policies. Policies are ranked by probability of achieving desired outcomes rather

23 than by optimisation or efficiency - robust policies perform well across a wide range of

24 scenarios compared to alternatives. 
1 However ABLUMs are used, it is important to realise that such models cannot yet be used

2 to predict the behaviour of specific households or communities precisely. Indeed, Moss et al.

3 (2001) assert that predictive social theories are impossible anyway, since the predictions

4 themselves can potentially change way the system operates. This does not mean that they

5 cannot be used as tools for understanding and exploring the processes involved in interactions

6 between the biophysical and socio-economic components of land use systems. Axelrod (1997)

7 has termed ABM the 'third way' of doing science, the first being the inductive approach, in

8 which patterns are discovered in empirical data, and the second being the deductive approach,

9 in which hypotheses are proposed and observations made of the real world to either prove or

10 disprove the predictions derived from these hypotheses. ABM, however, is an amalgamation

11 of these two approaches - like deduction, it starts with a set of explicit assumptions derived

12 from perceptions of the way the world works, but uses these to generate simulated data that

13 can be analysed inductively. Thus, rather than the empirical data for the inductive process

14 originating from direct observation of the real world, they emerge from a defined set of rules

15 developed from previous real-world observations.

Is agent-based modelling a passing fad? In our view, the prime challenge facing the

17 modellers is to show that they can provide new insights into complex natural resource systems

18 and their management that traditional approaches are not able to, but the outlook is promising.

\section{Acknowledgements}

20 We acknowledge financial support for this work under Development Activity RES-224-25-

210102 of the Rural Economy and Land Use (RELU) Programme, jointly funded by the

22 Economic and Social Research Council (ESRC), the Biotechnology and Biological Sciences

23 Research Council (BBSRC), the Natural Environment Research Council (NERC), and the

24 Scottish Executive Environment and Rural Affairs Department (SEERAD). 


\section{References}

2 An, L., Linderman, M., Qi, J., Shortridge, A. \& Liu, J., 2005. Exploring complexity in a human-environment system: An agent-based spatial model for multidisciplinary and multiscale integration. Annals of the Association of American Geographers 95(1):5479.

Axelrod, R., 1997. The complexity of cooperation: agent-based models of competition and collaboration. Princeton Studies in Complexity. Princeton University Press, Princeton, New Jersey. 232 pp.

Balmann, A., 1997. Farm-based modelling of a regional structural change: a cellular automata approach. European Review of Agricultural Economics 24:85-108.

Balmann, A., Happe, K., Kellermann, K. \& Kleingarn, A., 2002. Adjustment costs of agrienvironment policy switchings: an agent-based analysis of the German region Hohenlohe. In: M. Janssen (Editor), Complexity and Ecosystem Management: The Theory and Practice of Multi-agent Systems. Edward Elgar, Cheltenham, UK, pp. 127-157.

Barreteau, O. \& Bousquet, F., 2000. SHADOC: A multi-agent model to tackle viability of irrigated systems. Annals of Operations Research 94:139-162.

Barreteau, O., Bousquet, F. \& Attonaty, J.-M., 2001. Role-playing games for opening the black box of multi-agent systems: method and lessons of its application to Senegal River Valley irrigated systems. Journal of Artificial Societies and Social Simulation 4(2): $\underline{\text { http://www.soc.surrey.ac.uk/JASSS/4/2/5.html. }}$

Becu, N., Perez, P., Walker, A., Barreteau, O. \& Page, C.L., 2003. Agent based simulation of a small catchment water management in northern Thailand - description of the CATCHSCAPE model. Ecol. Modelling 170(2-3):319-331. 
1 Berger, T., 2001. Agent-based spatial models applied to agriculture: a simulation tool for technology diffusion, resource use changes and policy analysis. Agric. Econ. 25:245260.

Berger, T. \& Ringler, C., 2002. Trade-offs, efficiency gains, and technical change: modelling water management and land use within a multiple-agent framework. Quarterly Journal of International Agriculture 41(1/2):119-144.

Boero, R. \& Squazzoni, F., 2005. Does empirical embeddedness matter? Methodological issues on agent-based models for analytical social science. Journal of Artificial Societies and Social Simulation 8(4).

Boissau, S., Anh, H.L. \& Castella, J.C., 2004. The SAMBA role play game in northern Vietnam: An innovative approach to participatory natural resource management. Mountain Research and Development 24(2):101-105.

Bousquet, F., Barreteau, O., d'Aquino, P., Etienne, M., Boissau, S., Aubert, S., Le Page, C., Babin, D. \& Castella, J.-C., 2002. Multi-agent systems and role games: collective learning processes for ecosystem management. In: M. Janssen (Editor), Complexity and Ecosystem Management: The Theory and Practice of Multi-agent Systems. Edward Elgar, Cheltenham, UK, pp. 248-285.

Bousquet, F. \& Le Page, C., 2004. Multi-agent simulations and ecosystem management: a review. Ecol. Modelling 176:313-332.

Brown, D.G., Page, S.E., Riolo, R. \& Rand, W., 2004. Agent-based and analytical modelling to evaluate the effectiveness of greenbelts. Environmental Modelling and Software 19:1097-1109.

Carpenter, S.R. \& Cottingham, K.L., 2002. Resilience and the restoration of lakes. In: L.H. Gunderson \& L. Pritchard Jr (Editors), Resilience and the Behavior of Large Scale Ecosystems. Island Press, Washington D C, pp. 51-70. 
1 Castella, J.C., Trung, T.N. \& Boissau, S., 2005. Participatory simulation of land-use changes in the northern mountains of Vietnam: the combined use of an agent-based model, a role-playing game, and a geographic information system. Ecology and Society 10(1).

d'Aquino, P., Le Page, C., Bousquet, F. \& Bah, A., 2003. Using self-designed role-playing games and a multi-agent system to empower a local decision-making process for land use management: The SelfCormas experiment in Senegal. Journal of Artificial Societies and Social Simulation 6(3):5 [online at http://jasss.soc.surrey.ac.uk/6/3/5.html].

Deadman, P., Robinson, D., Moran, E. \& Brondizio, E., 2004. Colonist household decisionmaking and land-use change in the Amazon Rainforest: an agent-based simulation. Environment and Planning B: Planning and Design 31(5):693 - 709.

Dean, J.S., Gumerman, G.J., Epstein, J.M., Axtell, R.L., Swedlund, A.C., Parket, M.T. \& McCarroll, S., 2000. Understanding Anasazi cultural change through agent-based modelling. In: T.A. Kohler \& G.J. Gumerman (Editors), Dynamics in Human and Primate Studies: Agent-Based Modeling of Social and Spatial Processes. Oxford University Press, New York and Oxford, pp. 179-206.

Deffuant, G., Huet, S., Bousset, J.P., Henriot, J., Amon, G. \& Weisbuch, G., 2002. Agentbased simulation of organic farming conversion in Allier département. In: M. Janssen (Editor), Complexity and Ecosystem Management: The Theory and Practice of Multiagent Systems. Edward Elgar, Cheltenham, UK, pp. 158-187.

Epstein, J.M. \& Axtell, R., 1996. Growing Artificial Societies: Social Science from the Bottom Up. Brookings Institute, Washington DC.

Etienne, M., Le Page, C. \& Cohen, M., 2003. A step-by-step approach to building land management scenarios based on multiple viewpoints on multi-agent system simulations. Jasss-the Journal of Artificial Societies and Social Simulation 6(2):2. 
1 Evans, T.P. \& Kelley, H., 2004. Multi-scale analysis of a household level agent-based model of landcover change. Journal of Environmental Management 72:57-72.

Ferber, J., 1999. Multi-Agent Systems: An Introduction to Distributed Artificial Intelligence. Addison-Wesley Longman, Harlow, United Kingdom. 509 pp.

Gotts, N.M., Polhill, J.G. \& Law, A.N.R., 2003a. Agent-based simulation in the study of social dilemmas. Artificial Intelligence Review 19:3-92.

Gotts, N.M., Polhill, J.G. \& Law, A.N.R., 2003b. Aspiration levels in a land use simulation. Cybernetics and Systems 34(8):663-683.

Grimm, V., Wyszomirski, T., Aikman, D. \& Uchmanski, J., 1999. Individual-based modelling and ecological theory: synthesis of a workshop. Ecol. Modelling 115:275-282.

Happe, K., 2004. Agricultural policies and farm structures: agent-based modelling and application to EU policy reform. (Studies on the Agricultural and Food Sector in Central and Eastern Europe, Vol. 30). Institut für Agrarentwicklung in Mittel- und Osteuropa (IAMO), Halle, Germany. 291 pp.

Hare, M. \& Deadman, P., 2004. Further towards a taxonomy of agent-based simulation models in environmental management. Mathematics and Computers in Simulation $64: 25-40$.

Hoffmann, M., Kelley, H. \& Evans, T., 2002. Simulating land-cover change in South-Central Indiana: an agent-based model of deforestation and afforestation. In: M. Janssen (Editor), Complexity and Ecosystem Management: The Theory and Practice of Multiagent Systems. Edward Elgar, Cheltenham, UK, pp. 218-247.

Huigen, M.G.A., 2004. First principles of the MameLuke multi-actor modelling framework for land use change, illustrated with a Philippine case study. Journal of Environmental Management 72:5-21. 
1 Huston, M., DeAngelis, D. \& Post, W., 1988. New computer models unify ecological theory. Bioscience 38:682-691.

Izquierdo, L., Gotts, N.M. \& Polhill, J.G., 2004. Case based reasoning, social dilemmas, and a new equilibrium concept. Journal of Artificial Societies and Social Simulation 7(3):1 [online at: http://jasss.soc.surrey.ac.uk/7/3/1.html].

Izquierdo, L.R., Gotts, N.M. \& Polhill, J.G., 2003. FEARLUS-W: An agent-based model of river basin land use and water management. In: M. Dijst, P. Schot \& K. de Jong (Editors), Framing Land Use Dynamics: Integrating knowledge on spatial dynamics in socio-economic and environmental systems for spatial planning in western urbanized countries. Faculty of Geographical Sciences, Utrecht University, Utrecht, The Netherlands, pp. 163-165.

Janssen, M.A., 2001. An exploratory integrated model to assess management of lake eutrophication. Ecol. Modelling 140:111-124.

Janssen, M.A., Walker, B.H., Langridge, J. \& Abel, N., 2000. An adaptive agent model for analysing co-evolution of management and policies in a complex rangeland system. Ecol. Modelling 131:249-268.

Kohler, T.A. \& Gumerman, G.J., 2000. Dynamics in Human and Primate Societies: Agentbased Modelling of Social and Spatial Processes. Sante Fe Institute Studies in the Sciences of Complexity. Oxford University Press, Oxford. 398 pp.

Kohler, T.A., Kresl, J., West, C.V., Carr, E. \& Wilshusen, R.H., 2000. Be there then: a modelling approach to settlement determinants and spatial efficiency among late ancestral populations of the Mesa Verde region, U S Southwest. In: T.A. Kohler \& G.J. Gumerman (Editors), Dynamics in Human and Primate Studies: Agent-Based Modeling of Social and Spatial Processes. Oxford University Press, New York and Oxford, pp. 145-178. 
1 Lansing, J.S. \& Kremer, J.N., 1993. Emergent properties of Balinese water temple networks: coadaptation on a rugged fitness landscape. American Anthropologist 95:97-114.

Lempert, R., 2002. Agent-based modeling as organizational and public policy simulators. Proceedings of the National Academy of Science USA 99:7195-7196.

Ligtenberg, A., Wachowicz, M., Bregt, A.K., Beulens, A. \& Kettenis, D.L., 2004. A design and application of a multi-agent system for simulation of multi-actor spatial planning. Journal of Environmental Management 72:43-55.

Loibl, W. \& Toetzer, T., 2003. Modeling growth and densification processes in suburban regions - simulation of landscape transition with spatial agents. Environmental Modelling \& Software 18(6):553-563.

Lynam, T., 2002. Scientific measurements and villagers' knowledge: an integrative multiagent model from the semi-arid areas of Zimbabwe. In: M. Janssen (Editor),

Manson, S.M., 2004. The SYPR Integrative Assessment Model: Complexity in Development. Complexity and Ecosystem Management: The Theory and Practice of Multi-agent

Manson, S.M., 2005a. Agent-based modeling and genetic programming for modeling land change in the Southern Yucatán Peninsular Region of Mexico. Agricul. Ecosyst.

Manson, S.M., 2005b. Land use in the southern Yucatan peninsular region of Mexico: scenarios of population and institutional change. Computers, Environment, and Urban Systems 30(3):230-253. 
1 Matthews, R. \& Selman, P., 2006. Landscape as a focus for integrating human and environmental processes. Journal of Agricultural Economics 57(2):199-212.

Matthews, R.B., 2006. The People and Landscape Model (PALM): towards full integration of human decision-making and biophysical simulation models. Ecol. Modelling 194(4):329-343.

Matthews, R.B. \& Pilbeam, C.J., 2005. Modelling the long-term sustainability of maize/millet cropping systems in the mid-hills of Nepal. Agriculture, Ecosystems \& Environment 111(1-4):119-139.

Matthews, R.B. \& Stephens, W. (Editors), 2002. Crop-Soil Simulation Models: Applications in Developing Countries. CAB International, Wallingford, UK. 277 pp.

McCown, R.L., 2002a. Changing systems for supporting farmers' decisions: problems, paradigms, and prospects. Agric. Syst. 74:179-220.

McCown, R.L., 2002b. Locating agricultural decision support systems in the troubled past and socio-technical complexity of 'models for management'. Agric. Syst. 74:11-25.

Milner-Gulland, E.J., Kerven, C., Behnke, R., Wright, I.A. \& Smailov, A., 2006. A multiagent system model of pastoralist behaviour in Kazakhstan. Ecological Complexity $3: 23-36$.

Möhring, M. \& Troitzsch, K.G., 2001. Lake Anderson revisited by agents. Journal of Artificial Societies and Social Simulation 4(3):1 [online at: http://jasss.soc.surrey.ac.uk/4/3/1.html].

Moss, S., Pahl-Wostl, C. \& Downing, T., 2001. Agent-based integrated assessment modelling: the example of climate change. Integrated Assessment 2:17-30.

Otter, H.S., van der Veen, A. \& de Vriend, H.J., 2001. ABLOoM: Location behaviour, spatial patterns, and agent-based modelling. Journal of Artificial Societies and Social Simulation 4(4):2 (Online at http://jasss.soc.surrey.ac.uk/4/4/2.html). 
1 Parker, D.C., Manson, S.M., Janssen, M.A., Hoffmann, M.J. \& Deadman, P., 2002. Multiagent systems for the simulation of land-use and land-cover change: a review. Annals of the Association of American Geographers 93(2):316-340.

Parker, D.C. \& Meretsky, V., 2004. Measuring pattern outcomes in an agent-based model of edge-effect externalities using spatial metrics. Agricul. Ecosyst. Environ. 101:233250.

Polhill, J.G., Gotts, N.M. \& Law, A.N.R., 2001. Imitative versus non-imitative strategies in a land use simulation. Cybernetics and Systems 32(1-2):285-307.

Prabhu, R., Haggith, M., Mudavanhu, H., Muetzelfeldt, R. \& Standa-Gunda, W., 2003. ZimFlores: A model to advise co-management of the Mafungautsi Forest in Zimbabwe. Small-scale Forest Economics, Management and Policy 2(2):185-210.

Rajan, K.S. \& Shibasaki, R., 2001. A GIS based integrated land use/cover changemodel to study agricultural and urban land use changes. In: 22nd Asian Conference on Remote Sensing, 5-9 November 2001. Centre for Remote Imaging, Sensing, and Processing, National University of Singapore, Singapore.

Ramanath, A.M. \& Gilbert, N., 2004. The design of participatory agent-based social simulations. Journal of Artificial Societies and Social Simulation 7(4):1 [online] URL: http://jasss.soc.surrey.ac.uk/7/4/1.html.

Sanders, L., Pumain, D., Mathian, H., Guérin-Pace, F. \& Bura, S., 1997. SIMPOP - a multiagent system for the study of urbanism. Environment and Planning B: Planning and Design 24:287-305.

Scheffer, M. \& Carpenter, S.R., 2003. Catastrophic regime shifts in ecosystems: linking theory to observation. Trends in Ecology and Evolution 18(12):648-656.

Sengupta, R., Lant, C., Kraft, S., Beaulieu, J., Peterson, W. \& Loftus, T., 2005. Modeling enrollment in the Conservation Reserve Program by using agents within spatial 
decision support systems: an example from southern Illinois. Environment and Planning B-Planning \& Design 32(6):821-834.

Sinclair, T.R. \& Seligman, N.a.G., 1996. Crop modelling: from infancy to maturity. Agron. J. 88(5):698-703.

Stephens, W. \& Middleton, T., 2002. Why has the uptake of decision-support systems been so poor? In: R.B. Matthews \& W. Stephens (Editors), Crop-Soil Simulation Models: Applications in Developing Countries. CAB International, Wallingford, UK, pp. 129147.

Torrens, P., 2002. SprawlSim: Modelling sprawling urban growth using automata-based models. In: D.C. Parker, T. Berger \& S.M. Manson (Editors), Agent-Based Models of Land-Use and Land-Cover Change: Report and Review of an International Workshop, October 4-7, 2001. LUCC Focus 1 Office, Anthropological Center for Training and Research on Global Environmental Change, Indiana University, Indiana, pp. 72-78.

van den Belt, M., 2004. Mediated Modelling: A Systems Dynamic Approach to Environmental Consensus Building. Island Press, Washington DC. 339 pp.

Vanclay, J.K., Haggith, M. \& Colfer, C., 2003. Participation and model building: lessons learned from the Bukittinggi workshop. Small-scale Forest Economics, Management and Policy 2(2):135-154.

Verburg, P.H., 2006. Simulating feedbacks in land use and land cover change models. Landscape Ecology 21:1171-1183.

Weisbuch, G., 2000. Environment and institutions: a complex dynamical systems approach. Ecological Economics 34:381-391.

Weisbuch, G. \& Boudjema, G., 1999. Dynamical aspects in the adoption of agrienvironmental measures. Advances in Complex Systems 2:11-36. 
